University of Texas at El Paso

ScholarWorks@UTEP

Open Access Theses \& Dissertations

2021-05-01

\title{
A Longitudinal Study of Interprofessional Education in Graduate Students from Rehabilitation Sciences
}

Francesca Julia Hernandez

University of Texas at El Paso

Follow this and additional works at: https://scholarworks.utep.edu/open_etd

Part of the Speech and Hearing Science Commons, and the Speech Pathology and Audiology Commons

\section{Recommended Citation}

Hernandez, Francesca Julia, "A Longitudinal Study of Interprofessional Education in Graduate Students from Rehabilitation Sciences" (2021). Open Access Theses \& Dissertations. 3266.

https://scholarworks.utep.edu/open_etd/3266

This is brought to you for free and open access by ScholarWorks@UTEP. It has been accepted for inclusion in Open Access Theses \& Dissertations by an authorized administrator of ScholarWorks@UTEP. For more information, please contact Iweber@utep.edu. 


\section{A LONGITUDINAL STUDY OF INTERPROFESSIONAL EDUCATION IN GRADUATE STUDENTS FROM REHABILITATION SCIENCES}

FRANCESCA JULIA HERNANDEZ

Master's Program in Speech-Language Pathology

APPROVED:

Patricia Lara, Ph.D., CCC-SLP

Connie Summers, Ph.D., CCC-SLP

Celia Pechak, PT, Ph.D.

Deena Peterson, M.S., CCC-SLP

Stephen Crites, Ph.D.

Dean of the Graduate School 


\section{Copyright (C)}

by

Francesca Julia Hernandez

2021 


\section{A LONGITUDINAL STUDY OF INTERPROFESSIONAL EDUCATION IN GRADUATE STUDENTS FROM REHABILITATION SCIENCES}

by

FRANCESCA JULIA HERNANDEZ, B.S.

\section{THESIS}

Presented to the Faculty of the Graduate School of The University of Texas at El Paso

in Partial Fulfillment

of the Requirements

for the Degree of

MASTER OF SCIENCE

Department of Speech-Language Pathology

THE UNIVERSITY OF TEXAS AT EL PASO

May 2021 


\section{Acknowledgments}

Firstly, I would like to thank my thesis advisor, Dr. Patricia Lara, for her guidance and encouragement throughout this process. I would like to express my gratitude to my committee members, Dr. Connie Summers, Dr. Celia Pechak, and Ms. Deena Peterson, for their time and valuable feedback. I am thankful to have had the opportunity to work alongside such a remarkable and knowledgeable group of professionals in the field of rehabilitation sciences.

I would also like to thank my family and friends for their endless love and support throughout my educational career and during the completion of my thesis. I know that this accomplishment would not have been possible without them.

Lastly, I would like to thank the College of Health Sciences (CHS) for their investment in our research of interprofessional education. This project was funded through the CHS Grant for Strategic Transformation on Interprofessional Education. 


\begin{abstract}
Background: The importance of interprofessional collaboration (IPC) and interprofessional education (IPE) have been well recognized in the healthcare field and health professions programs. However, the long-term benefits of IPE experiences for students from various health professions has not been well investigated.

Purpose: The purpose of this study was to examine the long-term effectiveness of IPE experiences on rehabilitation sciences graduate students' interprofessional knowledge and perceptions of other disciplines' roles and responsibilities across time.

Methods: A group of seventy-one students from occupational therapy (OT), physical therapy (PT), and speech-language pathology (SLP) graduate programs at the University of Texas at El Paso (UTEP) were recruited to participate in this study. Participants' knowledge of interprofessional practice and perceptions of other disciplines' roles and responsibilities were measured across participants' first year of graduate school using a pre-survey and two-post surveys. The surveys included demographic questions, questions from the Interprofessional Attitudes Scales (IPAS), and an open-ended case-study question.

Results: Participants' IPAS scores and responses on the open-ended case-study question revealed statistically significant differences across time, which suggests that participants' knowledge and perceptions increased as a result of participation in IPE experiences.
\end{abstract}




\section{Table of Contents}

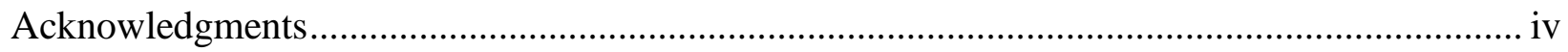

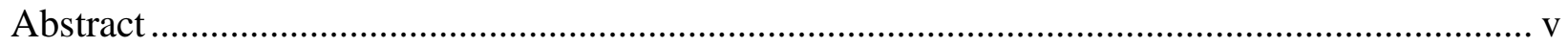

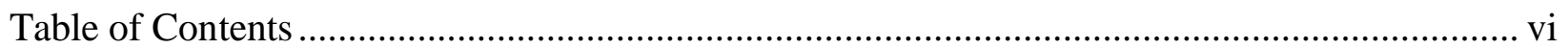

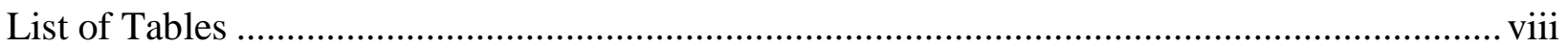

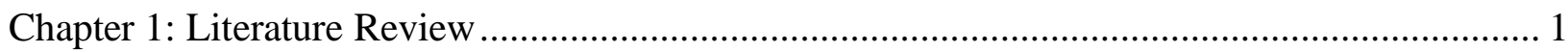

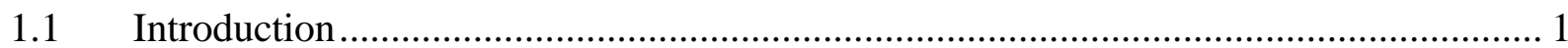

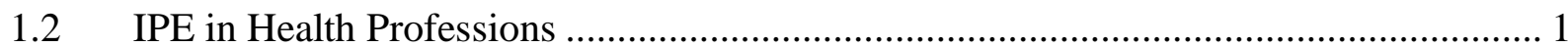

$1.3 \quad$ IPEC Core Competencies ……………………................................................. 3

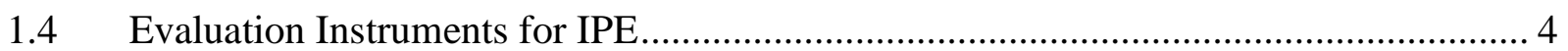

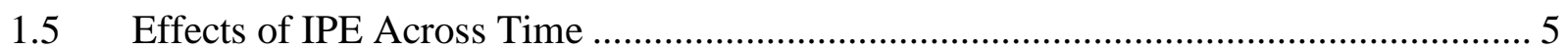

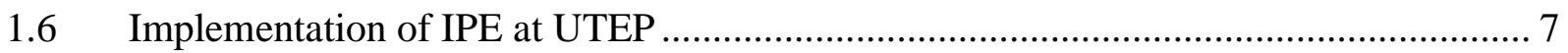

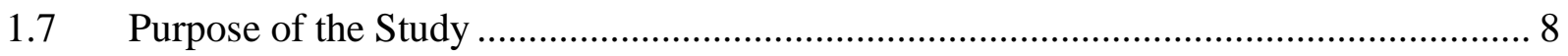

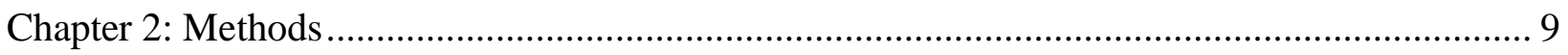

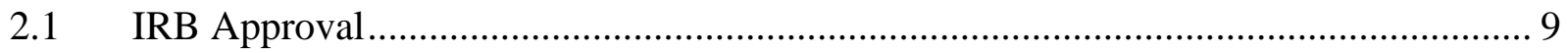

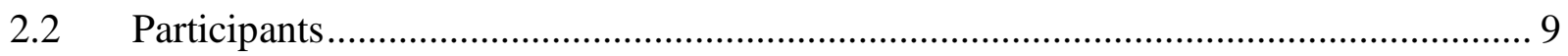

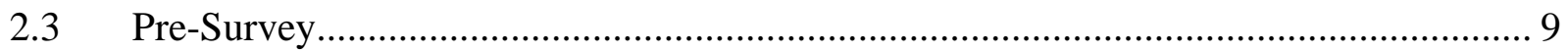

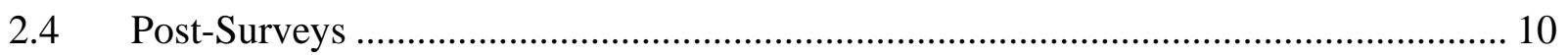

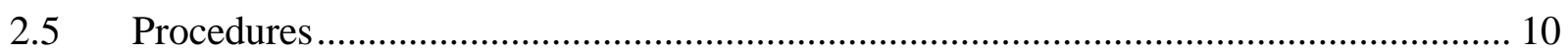

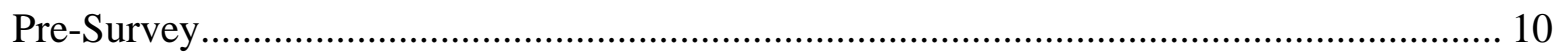

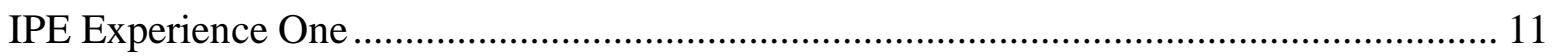

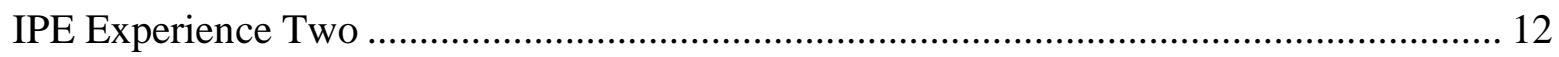

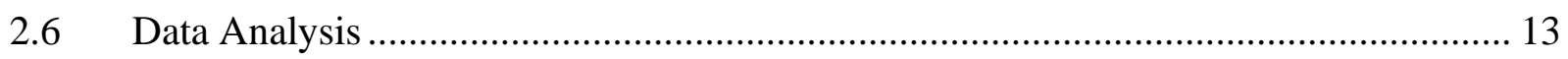

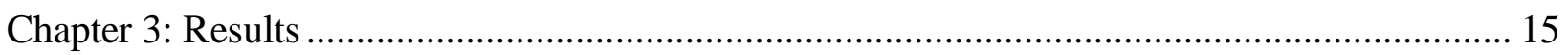

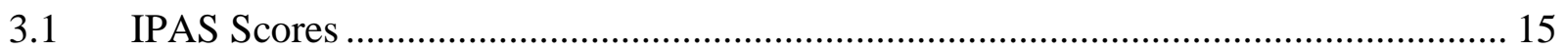

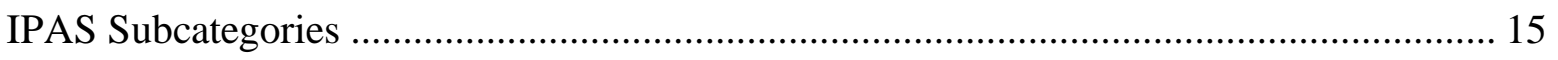

Between Subjects - Program, Gender, Ethnicity ............................................................... 17

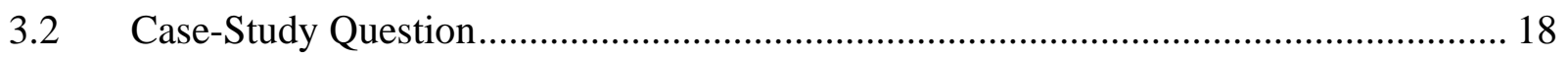

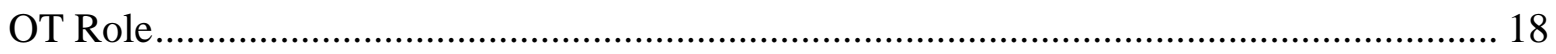

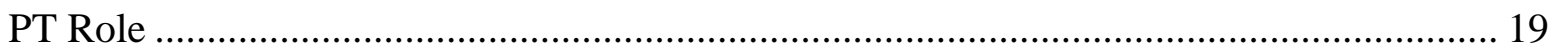

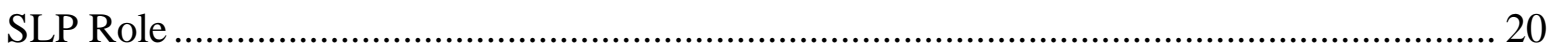

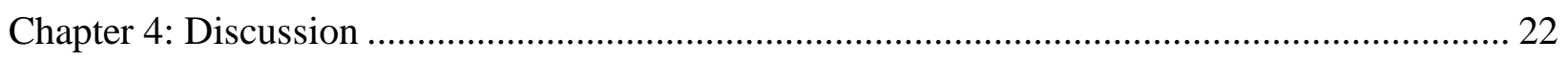

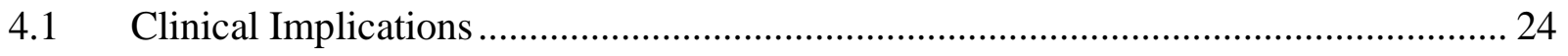

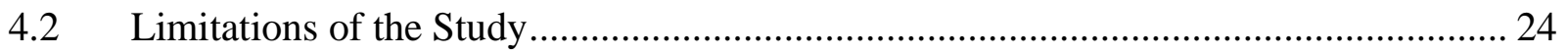




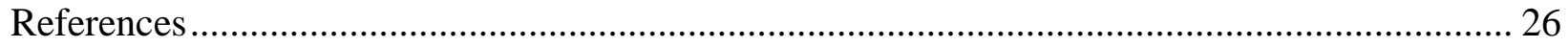

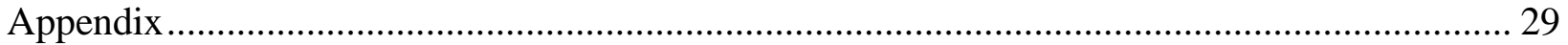

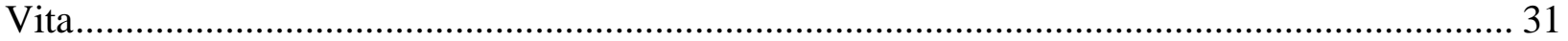




\section{List of Tables}

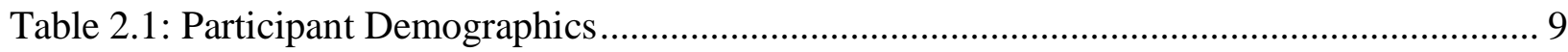

Table 3.1: IPAS Scores Differences Across Time By Subcategory and Item ........................... 16

Table 3.2: Differences By Program on IPAS Item 3.1 (Post-Survey Two)............................... 17

Table 3.3: Differences By Program on IPAS Item 3.2 (Pre-Survey)........................................ 18

Table 3.4: Differences By Program on IPAS CC Subcatefory (Post-Survey Two) .................... 18

Table 3.5: Differences By Gender on IPAS PC Subcatergory (Post-Survey Two) ..................... 18

Table 3.6: Most Commonly Used Categories for OT Role ................................................... 19

Table 3.7: Most Commonly Used Categories for PT Role ..................................................... 19

Table 3.8: Most Commonly Used Categories for SLP Role.................................................. 20 


\section{Chapter 1: Literature Review}

\subsection{Introduction}

Interprofessional collaboration (IPC) and interprofessional education (IPE) are critical components for impacting the quality of services for healthcare patients (Buring et al., 2009; Johnson \& Freeman, 2014; Lawlis, Anson, \& Greenfield, 2014). The purpose of this study was to evaluate the effectiveness of interprofessional education (IPE) experiences in rehabilitation sciences students enrolled in occupational therapy (OT), physical therapy (PT), and speech-language pathology (SLP) graduate programs. A pre-survey and two-post-surveys were used to measure changes in participants' interprofessional knowledge and perceptions of other disciplines' roles and responsibilities across participants' first year of graduate school.

\subsection{IPE in Health Professions}

Currently numerous challenges exist in the U.S. healthcare system. These challenges include an increased aging population and increased incidence of complex and long-term health conditions. The complexity of patients' healthcare needs requires healthcare professionals to work collaboratively to improve patient outcomes (Vincent, 2015). IPC is a critical component in ensuring that healthcare goals are met across a variety of professions (D'Amour \& Oandasan, 2005). In addition to improving patient outcomes, IPC has been associated with improving the quality of patient care, reducing costs by decreasing the duration of patients' stays, and minimizing medical errors. Evidence in the literature further supports that patients receive overall safer and higher quality care when healthcare professionals communicate effectively and understand each other's roles and responsibilities as part of an interdisciplinary team (Jones \& Jones, 2011; McDonald et al., 2009; Sargeant, Loney, \& Murphy, 2008; Suter et al., 2009). 
IPE occurs when individuals from two or more professions come together to learn with, from, and about each other in a collaborative environment (World Health Organization [WHO], 2010). The goal of IPE efforts is to develop the knowledge, attitudes, and skills necessary for students to become effective members of interdisciplinary teams, and in turn, provide collaborative patient-centered care (Buring et al., 2009; Reeves, Perrier, Goldman, Freeth, \& Zwarenstein, 2013). IPE is ideally incorporated throughout the course of a complete curriculum. Active student participation and planning, commitment, and facilitation by faculty members are essential components for maximizing the effectiveness of IPE experiences (Reeves, Tassone, Parker, Wagner, \& Simmons, 2012). In contrast, absence of these components can result in ineffective IPE experiences, which can create further misunderstanding between disciplines, decreased knowledge of disciplines' roles and responsibilities, decreased team communication, and poor quality of teamwork (Reeves, Zwarenstein, Goldman, Barr, Freeth, Hammick, \& Koppel, 2009).

IPE within health professions programs can involve a number of different disciplines. In a recent systematic review, Fox and colleagues (2018), identified students from the following professions to be most commonly involved in interprofessional teamwork teaching: medicine, nursing, pharmacy, dentistry, PT, OT, SLP, respiratory therapy, social work, nutrition, and paramedic. Additionally, the review identified the most common teaching methods for IPE experiences. The most frequently used method to teach IPE is simulated learning. This was followed by experiential learning and active learning via workshops, case studies, discussions, presentations, and role-played situations. Lastly, the review found that IPE experiences were either required or optional as part of students' curriculum (Fox et al., 2018). 
IPE's recognition as an essential component in preparing health professions students to become effective members in interdisciplinary teams has led many health professions accrediting bodies to incorporate IPE standards into their accreditation process. These accrediting bodies include the Liaison Committee on Medical Education, the Accreditation Commission for Education in Nursing, and the American Council of Pharmacy Education, among others. However, not all accrediting bodies provide explicit competencies for implementing this educational component (Fox et al., 2018). To address this issue, the Interprofessional Education Collaborative (IPEC) identified four interprofessional core competency domains for interprofessional collaborative practice. The IPEC core competencies were developed to provide a foundation for IPE, while simultaneously guiding and coordinating IPE efforts at the educational and professional levels (Interprofessional Education Collaborative [IPEC], 2016).

\subsection{IPEC Core Competencies}

The Core Competencies for Interprofessional Collaborative Practice as established by IPEC are: Values/Ethics for Interprofessional Practice; Roles/Responsibilities; Interprofessional Communication; and Teams and Teamwork (2016). IPEC is supported by various institutional members, including the American Speech Language and Hearing Association (ASHA), American Physical Therapy Association (APTA), American Occupational Therapy Association (AOTA), Association of Schools of Allied Health Professions (ASAHP), Council of Social Work Education (CSWE), and others. In addition to creating these core competencies, IPEC identified the necessity for the establishment and use of assessment instruments to measure interprofessional competencies. 


\subsection{Evaluation Instruments for IPE}

With the expanding implementation of IPE in health professions programs, various tools have been developed to evaluate the effectiveness of IPE. In a review of the literature, Marlow, Bisbey, Lacerenza, and Salas (2018) identified 70 measures used for assessing health care team performance. Ratings were provided for each measure's reliability, validity, general characteristics, and teamwork content to aid researchers and practitioners in the selection of appropriate measures for IPE. Reeves and Barr (2016) identified twelve key steps in the design, implementation, evaluation, and dissemination process for IPE. Step 10 addressed the use of evaluation instruments for IPE. The paper cited various commonly used tools for the evaluation of IPE, including the Interdisciplinary Education Perception Scale (IEPS), Interprofessional Collaboration Scale (ICS), Team Climate Inventory, Interaction Process Analysis (IPA) Instrument, Interprofessional Education Collaborative (IPEC) Assessment Tool, and Interprofessional Attitudes Scale (IPAS).

The IEPS consists of 18 items categorized into four subscales: competence and autonomy, perceived need for cooperation, perception of actual cooperation, and understanding others' value (Luecht, Madsen, Taugher, \& Petterson, 1990). The IEPS is used as a pre-test and post-test instrument to assess changes in students' professional perceptions as they relate to IPE. The ICS contains 13 items aimed to assess perceptions of IPC in the areas of communication, isolation, and accommodation amongst nurses, doctors, and other allied health professionals (Kenaszchuk, Reeves, Nicholas, \& Zwarenstein, 2010). The TCI is a 38-item self-report survey used to evaluate team climate amongst interdisciplinary healthcare teams (Anderson \& West, 1998). The TCI investigates four main components: vision, participative safety, task orientation, and support for intervention. The IPA instrument is used to analyze the socio-emotional and 
task-oriented components of interactions within teams (Greenwood \& Bales, 1950). The IPEC Competency Self-Assessment Tool consists of 42 items based on the IPEC core competencies programs (Dow, DiazGranados, Mazmanian, \& Retchin, 2014). This instrument is designed to measure competencies related to IPC in students from healthcare professions.

In the present study, the IPAS was utilized as a data collection instrument to provide a measure of students' attitudes and perceptions related to IPE and IPC. The IPAS consists of 27 items which are divided into 5 subscales. All IPAS items are rated on a 5 -point Likert scale $(1=$ strongly disagree, $5=$ strongly agree). The IPAS correlates the assessment of IPE to the IPEC Core Competencies and, thus, includes 18 items based on the IPEC core competencies. The remaining 9 items on the IPAS are based on the Readiness for Interprofessional Learning Scale (RIPLS), which aims to assess the readiness of students to engage in interprofessional learning. The IPAS was validated on 701 students recruited from four schools and colleges within the University of Utah Health Sciences Center (UUHSC). Results from the study revealed that the IPAS indicated good construct validity and internal consistency reliability, making it a useful tool for the assessment of interprofessional attitudes amongst health care professions (Norris et al., 2015).

\subsection{Effects of IPE Across Time}

Few studies have evaluated the long-term effectiveness of IPE on health professions students' attitudes, knowledge, and skills. A longitudinal study conducted by Curran, Sharpe, Flynn, and Button (2009) investigated the effects of IPE on undergraduate health professions students' attitudes towards IPE and teamwork. Participants consisted of undergraduate students enrolled in medical, nursing, pharmacy, and social work programs. IPE activities were integrated into the undergraduate curriculum in the form of case-based asynchronous learning, face-to-face 
small group learning, and panel discussions. Participants were asked to complete surveys routinely throughout the course of the three-year study. Findings revealed that the integration of extra-curricular IPE did not produce statistically significant effects on students' attitudes towards IPE or interprofessional teamwork. However, significant differences were reported in the satisfaction ratings of IPE for students from different health professions programs for all threeyears of the study. The mean scores across professions for students' attitudes towards IPE and teamwork also demonstrated statistically significant differences over the course of the study.

Pollard and Miers (2008) recruited 414 students enrolled in healthcare and social care programs to complete questionnaires pertaining to IPE across time. Questionnaires were collected at four points in time: upon entry to students' educational programs, during the second year of the students' programs, at the time of qualification for practice, and 9-12 months after engaging in qualified practice. Results revealed that students who engaged in IPE during their educational curriculum, prior to beginning professional practice, demonstrated increased confidence in skills, interprofessional relationships, and interprofessional communication.

In a longitudinal study by Arenson and colleagues (2014), students from medicine, nursing, occupational therapy, physical therapy, pharmacy, and couple and family therapy participated in a health mentors program (HMP) to promote IPE. Participants formed interprofessional teams and completed modules collaboratively over the course of two years. Outcome measures utilized in the study were interprofessional scales, focus groups, and reflection papers. Results revealed that participants demonstrated significant increases in attitudes towards team care from baseline to the end of the two-year experience. Furthermore, participants exhibited increases in knowledge and respect for other healthcare professionals' 
scope of practice. Additional longitudinal studies aimed at evaluating the long-term effects of IPE are currently underway, with results yet to be disseminated (Darlow et al, 2018).

\subsection{Implementation of IPE at UTEP}

At UTEP, faculty from the Doctor of Physical Therapy Program (DPT), the Master of Occupational Therapy Program (MOT) and the Speech-Language Pathology Program (SLP) came together in 2015 to provide IPE experiences to students from each of their respective programs. The first of these experiences involved an Interpreter-Use Training in which students were required to work collaboratively with a patient, a medical interpreter, and rehabilitation sciences students from DPT, MOT, and SLP in a role-play simulation (Pechak, Summers, \& Velasco, 2018; Summers, Gonzalez \& Pechak, 2015). Students' interprofessional knowledge was assessed from pre- to post-test. Findings from the study revealed that students' knowledge and attitudes related to interprofessional collaboration improved immediately after participating in IPE experiences. Further, results indicated that students' knowledge working with interpreters to provide patient-centered care also increased.

Following the initial IPE experience, faculty from the DPT, MOT, SLP, and other health professions programs formed the Health-Focused Interprofessional Education Community of Practice (HF-IPE CoP) to promote IPE experiences in their respective programs. The HF-IPE $\mathrm{CoP}$ has since developed various IPE experiences with a focus on vulnerable populations. In one experience coordinated by the HF-IPE CoP, students from DPT, MOT, SLP, and other health professions programs participated in an IPE activity centered on a case involving a transgender individual (Pechak, Summers, Schoen, Padilla, Lara, Velasco, \& Capshaw, 2018). This experience aimed to prepare students to competently serve vulnerable patients. Results from pre- 
to post-test measures revealed that students' interprofessional knowledge and knowledge working with special population increased. This experience additionally provided students with exposure to complex heath issues within the transgender community.

\subsection{Purpose of the Study}

Various studies have discovered an increase in students' interprofessional knowledge and attitudes after participating in a single IPE experience, however few studies have measured the effectiveness of these IPE experiences across time. Therefore, the purpose of the present study was to evaluate the long-term effectiveness of IPE experiences for students from rehabilitation sciences graduate programs. The objective of the study was to evaluate students' knowledge of interprofessional practice and perceptions of other disciplines' roles and responsibilities across their first year of graduate school. 


\section{Chapter 2: Methods}

\subsection{IRB Approval}

This study was approved by the Institutional Review Board (IRB) at UTEP.

\subsection{Participants}

Participants were recruited from the DPT, MOT, and SLP programs at UTEP to participate in this study. All participants were in the first-year of their graduate school programs. Seventy-one first-year students from OT, PT, and SLP graduate programs participated in the study. The average age of the participants was 22.6 years at the time the pre-survey was completed. Fifty participants (70.42\%) identified as female, seventeen (23.94\%) as male, and four participants $(5.63 \%)$ preferred not to respond. Forty-eight participants $(67.61 \%)$ identified as Hispanic, twenty-two participants (30.99\%) as non-Hispanic, and one participant $(1.41 \%)$ did not respond. Participant demographic information by program is summarized in Table 2.1.

\section{Table 2.1}

Participant demographics

\begin{tabular}{|c|c|c|c|c|}
\hline Program & $\mathbf{N}$ & Mean age & Gender (\% female) & Ethnicity (\% Hispanic) \\
\hline OT & 17 & 23.9 & $86.6 \%$ & $62.5 \%$ \\
\hline PT & 34 & 24.2 & $58.8 \%$ & $55.8 \%$ \\
\hline SLP & 20 & 24.8 & $85.0 \%$ & $95.0 \%$ \\
\hline
\end{tabular}

Note. $\mathrm{N}=$ sample size, $\mathrm{OT}=$ Occupational Therapy, $\mathrm{PT}=$ Physical Therapy, $\mathrm{SLP}=$ Speech-Language Pathology

\subsection{Pre-Survey}

A pre-survey and two post-surveys were adapted to measure the participants' interprofessional knowledge and attitudes across time. The pre-survey consisted of five demographic questions, twenty-seven rating questions from the IPAS (Norris et al., 2015), and one open-ended question about the roles and responsibilities of healthcare professionals in a case study format. Demographic questions included age, gender, ethnicity, and program. The IPAS consists of twenty-seven questions divided into five subscales. The five subscales 
are: Teamwork, Roles, and Responsibilities; Patient-Centeredness; Interprofessional Biases; Diversity and Ethics; and Community-Centeredness. Questions from the IPAS were rated on a 5point Likert scale $(1=$ strongly disagree, $5=$ strongly agree $)$. The case-study scenario that was provided was as follows: "A patient is referred to your rehab team after experiencing a stroke. He currently presents with right-sided weakness, dysphagia, and difficulty with speaking and following instructions. He has a neuropathic wound on his left foot. He presents with signs of depression and is worried about returning to work." The open-ended question pertaining to the case-study was, "What are the primary roles and responsibilities of the occupational therapist/physical therapist/speech-language pathologist?”.

\subsection{Post-Surveys}

Post-survey one and post-survey two were identical. The post-surveys followed the same format as the pre-survey with the exception of the demographic questions, which were excluded. The post-surveys included the following questions: twenty-seven rating questions from the IPAS (Norris et al., 2015), one open-ended question about the roles and responsibilities of healthcare professionals in a case study format, and one open-ended evaluation question. The open-ended evaluation question was, "What is the most important thing you learned today?"

\subsection{Procedures}

\section{Pre-Survey}

Participants completed a pre-survey during the first semester of their graduate school programs which was either in the summer or fall, followed by two post-surveys throughout the course of their first year. A research assistant visited a class for each program to explain the study and distribute the informed consent forms. Participants were then provided 
with a link to access and complete the pre-survey. Seventeen OT participants, thirty-four PT participants, and twenty SLP participants provided informed consent and responded to the presurvey.

\section{IPE Experience One}

Students participated in the first IPE experience during the fall of their first year, which involved an Interpreter-Use Training. The event was approximately 3.5 hours in duration. Upon arrival at the IPE experience, participants were instructed to sit with pre-assigned interprofessional groups consisting of OT, PT, and SLP students. Each group had at least one student from each program. Due to the unbalanced number of students enrolled in each program, some groups contained more than one SLP and/or PT student. The IPE experience consisted of the following three components: an overview of the Interpreter-Use Training, a simulated Interpreter-Use role-play, and a debrief session.

First, an overview of the Interpreter-Use Training was provided to all students at the beginning of the IPE experience. This component was approximately one hour in duration and consisted of a lecture presentation guided by faculty members. The presentation provided information pertaining to linguistic competence and safety in healthcare, as well as an overview of the enhanced CLAS Standards. Brief videos demonstrating the use of interpreters in different situations were also included. The presentation concluded with instructions and rules for the role-play.

For the second portion, participants alternated between two activities. For the first hour, half of the participants completed a simulated experience using an interpreter, while the other half received a more in-depth presentation about the ethics of interpreter-use. Then, the two groups of participants were instructed to switch activities for the following hour. For the 
simulation experience, participants were escorted to simulated hospital rooms. Participants were provided with a brief period to coordinate with their group members before beginning the roleplay. Second-year students from OT, PT, and SLP programs who were proficient Spanish speakers were recruited to serve as mock patients and interpreters in the role-play simulation. The participants of the current study took turns serving as the clinician and used a mock interpreter to complete an assessment of a mock patient who had sustained a cerebrovascular accident. Each participant had approximately 15 minutes to complete their portion of the assessment, or approximately 7.5 minutes if the group contained two participants from the same program. Faculty members were present in each simulation room to monitor the experience and prompt the participants when it was time to transition between the mock clinicians.

The third portion consisted of a large group debrief session with all the participants back together. During the session, participants took part in a semi-structured discussion about what they learned from using an interpreter and working with other professions. Participants were instructed to complete post-survey one either immediately following the IPE experience, or during class the following week. All participants completed post-survey one within one week of attending the IPE experience. Seventeen OT participants, thirty-four PT participants, and nineteen SLP participants completed post-survey one.

\section{IPE Experience Two}

Participants completed a second IPE experience the following semester, which involved a Transgender Case Study. The event was approximately 2.5 hours in duration. Upon arrival at the IPE experience, participants were instructed to sit with pre-assigned interprofessional groups 
consisting of OT, PT, SLP, rehabilitation counseling, nursing, pharmacy, social work, public health, and medical students.

At the start of the event, faculty members presented a brief overview of transgender terminology and health disparities. Participants were provided with written casestudy information about a transgender patient who had a diagnosis of a cerebrovascular accident. The case-study was divided into four sections and distributed one at a time. Questions were embedded in the case-study for the participants to discuss within their small groups at the table after each section. Small group discussions were then followed by a large group discussion of those questions. This process was repeated four times during the IPE experience. Faculty members circulated around the room throughout the event to facilitate discussion and encourage participation from students.

After all sections of the case-study had been completed and discussed, faculty members guided a large-group debrief session. Additional profession-specific debriefs within each program were conducted within the week following the IPE experience. Participants were also instructed to complete post-survey two during class that same week. All participants completed post-survey two within one week of attending the IPE experience. Seventeen OT participants, thirty-three PT participants, and twelve SLP participants completed post-survey two. Eight SLP participants were attending a conference on the same day as the second IPE experience, and therefore did not complete post-survey two.

\subsection{Data Analysis}

The quantitative data from the IPAS rating questions were analyzed using the following non-parametric tests. The Friedman test was performed to measure changes in scores across time (pre-test, post-test one, post-test two). Post hoc analysis with the Wilcoxon signed-rank test was 
utilized to compare paired data from pre- and post-tests measurements based on independent units. The Bonferroni correction was used to account for the use of many simultaneous tests by adjusting the p-values. The Kruskal-Wallis test was utilized to determine if statically significant differences existed for scores based on program, gender, and ethnicity.

The qualitative data from the open-ended case-study question was analyzed using content analysis. The author, a research assistant, and a faculty member independently read the participants' responses and identified common themes. They then met to discuss the themes they found and to develop categories and subcategories. They used the agreed upon categories and subcategories to independently code the participants' responses. From the independently coded responses, the team members reconvened and finalized codes for each response. 


\section{Chapter 3: Results}

\subsection{IPAS Scores}

\section{IPAS Subcategories}

Friedman tests were performed to determine if participants' ratings on the IPAS changed significantly across time. Post hoc analysis using the Wilcoxon signed-rated test with pairwise comparisons were performed with a Bonferroni correction for multiple comparisons. Pairwise comparison at the $\mathrm{p}<.017$ level was considered significant. Participants' scores were analyzed by median subcategory scores with the exception of the Interprofessional Biases subcategory, in which scores were analyzed by median item scores.

Subcategory 1: Teamwork, Roles, and Responsibilities (TRR). Participants's scores were found to be significantly different across time $(\chi 2(2)=16.237, p<.0001)$. Results from the post hoc analyses revealed statistically significant differences in this subcategory from presurvey $(\mathrm{Mdn}=1.68)$ to post-survey one $(\mathrm{Mdn}=2.30, \mathrm{p}=.005)$. Pairwise comparisons did not reveal statistically significant differences with the Bonferroni correction.

Subcategory 2: Patient-Centeredness (PC). Participants' scores were significantly different across time $(\chi 2(2)=9.160, p=.010)$. Post hoc analyses results revealed statistically significant differences from pre-survey $(\mathrm{Mdn}=1.85)$ to post-survey two $(\mathrm{Mdn}=2.04, \mathrm{p}=.015)$. Pairwise comparisons did not reveal statistically significant differences with the Bonferroni correction.

Subcategory 3: Interprofessional Biases (IB). Item 3.1 scores were statistically significantly different across time $(\chi 2(2)=16.853, \mathrm{p}<.0001)$. Results from the post hoc analyses revealed statistically significant differences from pre-survey $(\mathrm{Mdn}=1.76)$ to post-survey two 
$(\mathrm{Mdn}=2.34, \mathrm{p}<.001)$ and from post-survey one $(\mathrm{Mdn}=1.90)$ to post-survey two $(\mathrm{Mdn}=2.34$, $\mathrm{p}=.001$ ). Significant differences were not found from pre-survey to post-survey one.

Item 3.2 scores were statistically significantly different across time $(\chi 2(2)=8.926, p=$ .012). Post hoc analyses results revealed statistically significant differences from pre-survey $(\mathrm{Mdn}=1.78)$ to post-survey two $(\mathrm{Mdn}=2.20, \mathrm{p}=.001)$. Significant differences were not found from pre-survey to post-survey one or from post-survey one to post-survey two.

Item 3.3 scores were not statistically significantly different across time $(\chi 2(2)=8.014, p$ $=.018)$.

Subcategory 4: Diversity and Ethics (DE). Participants' scores were not statistically significantly different across time $(\chi 2(2)=3.073, \mathrm{p}=.215)$.

Subcategory 5: Community-Centeredness (CC). Participants' scores were not found to be significantly different across time $(\chi 2(2)=7.058, \mathrm{p}=.029)$.

\section{Table 3.1}

IPAS scores differences across time by subcategory and item

\begin{tabular}{c|ccc}
\multicolumn{1}{c}{ Subcategory } & Item & Chi square & p value $(<.017)$ \\
\hline TRR & & 16.237 & $<.0001^{*}$ \\
PC & 3.1 & 16.853 & $.010^{*}$ \\
IB & 3.2 & 8.926 & $<.0001^{*}$ \\
& 3.3 & 8.014 & $.012^{*}$ \\
DE & & 3.073 & .018 \\
CC & & 7.058 & .215 \\
& & & .029
\end{tabular}

Note. TRR $=$ Teamwork, Roles, and Responsibilities, $\mathrm{PC}=$ Patient-Centeredness, $\mathrm{IB}=$ Interprofessional Biases, $\mathrm{DE}=$ Diversity and Ethics, $\mathrm{CC}=$ Community-Centeredness 


\section{Between Subjects - Program, Gender, Ethnicity}

Kruskal-Wallis tests were performed to determine effects of program, gender, and ethnicity on IPAS ratings. If statistically significant differences were found in the case of program, pairwise comparisons were performed using Dunn's (1964) procedure with a Bonferroni correction for multiple comparisons. Adjusted p-values are presented.

Program. No significant differences were found based on Program for TRR, PC, DE, or IB for item 3.3. There were statistically significant differences for IB item 3.1 on post-survey two $(\chi 2(2)=6.853, p=.033)$. Significant differences were not found for this item on the presurvey or post-survey one. Post hoc pairwise comparisons revealed that the difference was between the OT (mean rank $=40.18$ ) and PT participants (mean rank $=27.85, \mathrm{p}=.031$ ). There were significant differences for IB item 3.2 for the pre-survey $(\chi 2(2)=6.731, \mathrm{p}=.035)$. Significant differences were not found for this item for post-survey one or post-survey two. Post hoc pairwise comparisons revealed that the difference was between the OT (mean rank $=27.09$ ) and PT participants (mean rank $=33.89, \mathrm{p}=.049$ ). There was also a significant difference for the CC subcategory based on program for post-survey two $(\chi 2(2)=11.427, \mathrm{p}=.003)$, but not for the pre-survey or post-survey one. Post hoc pairwise comparisons revealed that the difference was between the OT (mean rank $=39.68)$ and the PT programs (mean rank $=25.47, \mathrm{p}=.005)$.

\section{Table 3.2}

Differences by program on IPAS item 3.1 (post-survey two)

\begin{tabular}{|c|c|c|}
\hline Program & Mean Rank & p value \\
\hline OT & 40.18 & .031 \\
\hline PT & 27.85 & \\
\hline
\end{tabular}

Note. Chi Square $=6.853, \mathrm{p}=.033$ 
Table 3.3

Differences by program on IPAS item 3.2 (pre-survey)

\begin{tabular}{|c|c|c|}
\hline Program & Mean Rank & p value \\
\hline OT & 27.09 & .049 \\
\hline PT & 33.89 & \\
\hline
\end{tabular}

Note. Chi Square $=6.731, \mathrm{p}=.031$

Table 3.4

Differences by program on IPAS CC subcategory (post-survey two)

\begin{tabular}{|c|c|c|}
\hline Program & Mean Rank & p value \\
\hline OT & 39.68 & .005 \\
\hline PT & 25.47 & \\
\hline
\end{tabular}

Note. Chi Square $=11.427, \mathrm{p}=.003$

Gender. PC subcategory scores were found to be significantly different on post-survey two between male and female $(\chi 2(1)=4.774, \mathrm{p}=.029)$. Female participants rated themselves significantly higher than male participants in this domain.

Table 3.5

Differences by gender on IPAS PC subcategory (post-survey two)

\begin{tabular}{|c|c|}
\hline Gender & Mean Rank \\
\hline Female & 30.60 \\
\hline Male & 24.91 \\
\hline
\end{tabular}

Note. Chi Square $=4.774, \mathrm{p}=.029$

Ethnicity. No significant differences were found on the pre-survey, post-survey one, or post-survey two based on Ethnicity (p>.05).

\subsection{Case-Study Question}

Overall, participants recognized the role of evaluation more on post-survey one, compared to the pre-survey and post-survey two for all professions (OT, PT, SLP).

OT Role

SLP participants increased their recognition of fine motor from the pre-survey (15\%) to post-survey one (47\%) and post-survey two (25\%). Participants from all programs recognized 
activities of daily living (ADL) more from the pre-survey (OT $=53 \%, \mathrm{PT}=74 \%, \mathrm{SLP}=30 \%$ )

to post-survey one $(\mathrm{OT}=47 \%, \mathrm{PT}=79 \%, \mathrm{SLP}=58 \%)$ and post-survey two $(\mathrm{OT}=65 \%, \mathrm{PT}$

$=79 \%$, SLP $=42 \%)$. Statements about ADLs focused on improving independence in daily

activities, such as bathing, toileting, dressing, grooming, and, eating.

Table 3.6

Most common categories for OT role

\begin{tabular}{|c|c|c|c|}
\hline & Pre-Survey & Post-Survey One & Post-Survey Two \\
\hline \multirow[t]{5}{*}{ OT } & $(n=17)$ & $(n=17)$ & $(n=17)$ \\
\hline & $9(53 \%)-\mathrm{ADL}$ & $10(59 \%)$ - Evaluation & $11(65 \%)-\mathrm{ADL}$ \\
\hline & $9(53 \%)$ - Strength & $8(47 \%)-\mathrm{ADL}$ & $8(47 \%)$ - Mental Health \\
\hline & $7(41 \%)$ - Participation & $7(41 \%)$ - Cognition & $6(35 \%)$ - Participation \\
\hline & $6(35 \%)$ - Mental Health & $5(29 \%)$ - Participation & $4(24 \%)$ - Evaluation \\
\hline \multirow[t]{5}{*}{ PT } & $(n=34)$ & $(n=34)$ & $(n=33)$ \\
\hline & $25(74 \%)-\mathrm{ADL}$ & $27(79 \%)-\mathrm{ADL}$ & $26(79 \%)-\mathrm{ADL}$ \\
\hline & $10(29 \%)$ - Participation & $14(41 \%)$ - Participation & $13(39 \%)$ - Participation \\
\hline & $6(18 \%)$ - Strength & $6(18 \%)$ - Evaluation & $5(15 \%)$ - Strength \\
\hline & $4(12 \%)$ - Mobility & $4(12 \%)$ - Mobility & $5(15 \%)$ - Fine Motor \\
\hline \multirow[t]{5}{*}{ SLP } & $(n=20)$ & $(n=19)$ & $(n=12)$ \\
\hline & $7(35 \%)$ - Participation & $11(58 \%)-\mathrm{ADL}$ & $5(42 \%)-\mathrm{ADL}$ \\
\hline & $7(35 \%)$ - Mental Health & $9(47 \%)$ - Fine Motor & $4(33 \%)$ - Participation \\
\hline & $6(30 \%)-\mathrm{ADL}$ & $9(47 \%)$ - Evaluation & $3(25 \%)$ - Fine Motor \\
\hline & $5(25 \%)$ - Strength & $3(16 \%)$ - Participation & $3(25 \%)$ - Evaluation \\
\hline
\end{tabular}

Note. $\mathrm{ADL}=$ activities of daily living, $\mathrm{OT}=$ Occupational Therapy, $\mathrm{PT}=$ Physical Therapy, $\mathrm{SLP}=$ Speech-Language Pathology

\section{PT Role}

OT and SLP participants recognized mobility more from the pre-survey (OT $=41 \%$, SLP $=25 \%)$ to post-survey one $(\mathrm{OT}=94 \%, \mathrm{SLP}=89 \%)$ and post-survey two $(\mathrm{OT}=65 \%, \mathrm{SLP}=$ 75\%). OT and PT participants mentioned strength more from the pre-survey $(\mathrm{OT}=47 \%, \mathrm{PT}$ $=65 \%)$ to post-survey two $(\mathrm{OT}=76 \%, \mathrm{PT}=73 \%)$.Participants from all programs recognized wound care less from the pre-survey $(\mathrm{OT}=29 \%, \mathrm{PT}=32 \%, \mathrm{SLP}=45 \%)$ to post-survey one (OT $=24 \%, \mathrm{PT}=29 \%, \mathrm{SLP}=11 \%)$ and post-survey two $(\mathrm{OT}=29 \%, \mathrm{PT}=21 \%, \mathrm{SLP}=17 \%)$.

\section{Table 3.7}


Most common categories for PT role

\begin{tabular}{|c|c|c|c|}
\hline & Pre-Survey & Post-Survey One & Post-Survey Two \\
\hline \multirow[t]{5}{*}{ OT } & $(n=17)$ & $(n=17)$ & $(n=17)$ \\
\hline & $8(47 \%)$ - Strength & 16 (94\%) - Mobility & $13(76 \%)$ - Strength \\
\hline & 7 (41\%) - Mobility & $9(53 \%)$ - Evaluation & 11 (65\%) - Mobility \\
\hline & $5(29 \%)$ - Wound Care & 7 (41\%) - Strength & 5 (29\%) - Transfers \& Safety \\
\hline & $2(12 \%)-\mathrm{ADL}$ & $5(29 \%)$ - Transfers \& Safety & $5(29 \%)$ - Wound Care \\
\hline \multirow[t]{5}{*}{ PT } & $(n=34)$ & $(n=34)$ & $(n=33)$ \\
\hline & $22(65 \%)$ - Strength & 24 (71\%) - Mobility & $24(73 \%)$ - Strength \\
\hline & 17 (50\%) - Mobility & $22(65 \%)$ - Strength & $16(48 \%)$ - Mobility \\
\hline & $12(35 \%)$ - Participation & $13(38 \%)$ - Evaluation & $15(45 \%)$ - Participation \\
\hline & $11(32 \%)$ - Wound Care & $10(29 \%)$ - Wound Care & 7 (21\%) - Wound Care \\
\hline \multirow[t]{5}{*}{ SLP } & $(n=20)$ & $(n=19)$ & $(n=12)$ \\
\hline & 13 (65\%) - Strength & 17 (89\%) - Mobility & $9(75 \%)$ - Mobility \\
\hline & $9(45 \%)$ - Wound Care & $12(63 \%)$ - Evaluation & $6(50 \%)$ - Evaluation \\
\hline & $5(25 \%)$ - Mobility & $3(16 \%)$ - Strength & $5(42 \%)$ - Strength \\
\hline & $3(15 \%)$ - Evaluation & $2(11 \%)$ - Wound Care & $2(17 \%)$ - Wound Care \\
\hline
\end{tabular}

Note. OT $=$ Occupational Therapy, PT $=$ Physical Therapy, SLP $=$ Speech-Language Pathology

\section{SLP Role}

OT and PT participants increased their recognition of cognition from the pre-survey (OT $=41 \%, \mathrm{PT}=9 \%)$ to post-survey one $(\mathrm{OT}=71 \%, \mathrm{PT}=53 \%)$, which decreased at post-survey two $(\mathrm{OT}=18 \%, \mathrm{PT}=21 \%)$. OT and PT participants mentioned dysphagia more from the presurvey $(\mathrm{OT}=47 \%, \mathrm{PT}=58 \%)$ to post-survey one $(\mathrm{OT}=53 \%, \mathrm{PT}=71 \%)$ and post-survey two $(\mathrm{OT}=94 \%, \mathrm{PT}=97 \%)$. On the other hand, SLP participants recognized communication, including speech and language, more from the pre-survey (SLP $=70 \%)$ to post-survey one (SLP $=95 \%)$ and post-survey two $($ SLP $=100 \%)$.

Table 3.8 
Most common categories for SLP role

\begin{tabular}{|c|c|c|c|}
\hline & Pre-Survey & Post-Survey One & Post-Survey Two \\
\hline \multirow[t]{5}{*}{ OT } & $(n=17)$ & $(n=17)$ & $(n=17)$ \\
\hline & $14(82 \%)$ - Communication & $17(100 \%)$ - Communication & $16(94 \%)$ - Dysphagia \\
\hline & $8(47 \%)$ - Dysphagia & $12(71 \%)$ - Cognition & $14(82 \%)$ - Communication \\
\hline & $7(41 \%)$ - Cognition & $9(53 \%)$ - Dysphagia & $3(18 \%)$ - Cognition \\
\hline & $2(12 \%)$ - Participation & $5(29 \%)$ - Evaluation & $1(6 \%)-\mathrm{ADL}$ \\
\hline \multirow[t]{5}{*}{ PT } & $(n=34)$ & $(n=34)$ & $(n=33)$ \\
\hline & $33(97 \%)$ - Communication & $29(85 \%)$ - Communication & $32(97 \%)$ - Dysphagia \\
\hline & $20(58 \%)$ - Dysphagia & $24(71 \%)$ - Dysphagia & $28(85 \%)$ - Communication \\
\hline & $3(9 \%)$ - Cognition & $18(53 \%)$ - Cognition & $7(21 \%)$ - Cognition \\
\hline & $1(3 \%)$ - Mental Health & $9(26 \%)$ - Evaluation & $5(15 \%)$ - Evaluation \\
\hline \multirow[t]{5}{*}{ SLP } & $(n=20)$ & $(n=19)$ & $(n=12)$ \\
\hline & $18(90 \%)$ - Dysphagia & $18(95 \%)$ - Communication & $12(100 \%)$ - Communication \\
\hline & $14(70 \%)$ - Communication & $12(63 \%)$ - Dysphagia & $9(75 \%)$ - Dysphagia \\
\hline & $12(60 \%)$ - Cognition & $11(58 \%)$ - Evaluation & $8(67 \%)$ - Evaluation \\
\hline & $5(25 \%)$ - Evaluation & $10(53 \%)$ - Cognition & $7(58 \%)$ - Cognition \\
\hline
\end{tabular}

Note . $\mathrm{OT}=$ Occupational Therapy, $\mathrm{PT}=$ Physical Therapy, SLP $=$ Speech-Language Pathology 


\section{Chapter 4: Discussion}

The purpose of the current study was to evaluate the long-term effects of IPE experiences for rehabilitation sciences graduate students. This study specifically assessed changes in students' knowledge of interprofessional practice and perceptions of other disciplines' roles and responsibilities across their first year of graduate school. Findings from this study provide support for the implementation of IPE experiences in university health professions programs.

Overall, participants increased their knowledge and attitudes about interprofessional practice across time, as evidenced by changes in participants' IPAS rating scores (Norris et al., 2015). Statistically significant differences were found for the TRR, PC, and IB subcategories across at least two points in time (pre-survey and post-survey one, pre-survey and post-survey two, and/or post-survey one and post-survey two). These findings correlate with those from previous studies in which students' interprofessional knowledge increased after participation in one or more IPE experiences (Curran et al., 2009; Pollard \& Miers, 2008; Arenson et al., 2014; Pechak, Summers, \& Velasco, 2018; Summers, Gonzalez \& Pechak, 2015; Pechak et al., 2018).

Results from the between subjects analyses provided information about the effects of Program, Gender, and Ethnicity on participants' IPAS ratings. Findings revealed that there were statistically significant differences for Program between OT and PT participants on two items (IB 3.1 and IB 3.2), and one subcategory (CC). Significant differences were found on the measure of Gender on one subcategory (PC). This finding may be attributed to the participant groups being unbalanced due to more females participating in the study than males. No statistically significant differences were found on the basis of Ethnicity.

On the basis of Program, Item 3.1 indicated that OT participants rated themselves significantly higher in the measure of other professions having biases and making assumptions 
about them based on their profession. Whereas, PT participants rated themselves significantly lower on this item. These findings revealed that OT participants' perceptions of biased treatment that they received was greater than those of PT participants. Item 3.2 revealed that PT participants rated themselves as having significantly more prejudices or making more assumptions about other professions. In contrast, OT participants rated themselves significantly lower in this area. These findings suggest that PT participants either have significantly more prejudices towards other professions than OT participants, or that PT participants are more aware of their profession-specific prejudices. Comparison of OT and PT participants' ratings on the CC subcategory revealed that OT participants rated themselves significantly higher than PT participants in this area. These results suggest that OT participants place a greater importance on their role as healthcare professionals in the community.

On the basis of Gender, females rated themselves significantly higher than males in the area of PC. This finding suggests that female participants may value a more patient-centered approach to service delivery than male participants.

Participants from all programs increased their understanding of other disciplines' roles and responsibilities, as evidenced by participants' responses on the open-ended case-study question. Analysis of participants' responses on each survey provided specific information about participants' acquired knowledge in this area as a result of participation in the IPE experiences. For example, OT and SLP participants increased their understanding of PT's role in improving patients' mobility after participation in the two IPE experiences. Additionally, OT and PT participants increased their knowledge of SLP's role in dysphagia management at the time of the two post-surveys. Findings from the open-ended case study responses further revealed that the content of the IPE experiences influenced participants' knowledge of profession-specific roles 
and responsibilities. Due to the first IPE experience involving evaluation of a patient via a roleplay simulation, participants from all programs recognized the role of evaluation more on postsurvey one, than on the pre-survey or post-survey two. In the second IPE experience, participants worked collaboratively on a case-study for a patient from a vulnerable population. Subsequently, participants' responses following this IPE experience reflected a greater focus on patients' mental health and participation in life situations.

\subsection{Clinical Implications}

Results from this study support the finding that rehabilitation sciences graduate students benefit from participating in IPE experiences during their educational programs. Specifically, participation in IPE experiences increases students' interprofessional knowledge and perceptions of other professions' roles and responsibilities. IPE experiences are an effective method for developing the knowledge and skills needed for healthcare students to effectively engage in IPC upon beginning their professional careers. For this reason, IPE experiences positively impact the quality of patient care and patient outcomes.

\subsection{Limitations of the Study}

Convenience sampling was used to recruit participants enrolled in their first year of graduate school for rehabilitation sciences programs at UTEP. For this reason, participant groups were unbalanced in the variables of age, sex, ethnicity, and program. Additionally, participant attrition occurred due to a schedule conflict for SLP participants who attended a professional conference on the date of the second IPE experience. This attrition resulted in further imbalance between groups at the time of post-survey two. Lastly, this study did not control for participants' prior experience working in interprofessional settings and/or participants' interprofessional 
knowledge acquired from coursework and externship experiences during their graduate school curriculum. 


\section{References}

Anderson, N. R., \& West, M. A. (1998). Measuring climate for work group innovation: Development and validation of the team climate inventory. Journal of Organizational Behavior, 19(3), 235-258. doi:10.1002/(sici)1099-1379(199805)19:33.0.co;2-c

Buring, S. M., Bhushan, A., Brazeau, G., Conway, S., Hansen, L., \& Westberg, S. (2009). Keys to successful implementation of interprofessional education: Learning, location, faculty development and curricular themes. American Journal of Pharmaceutical Education, 73(4), Article 60. Retrieved from http://www.aacp.org doi:10.5688/aj730460

D’Amour D., \& Oandasan, I. (2005). Interprofessionality as the field of interprofessional practice and interprofessional education: An emerging concept. Journal of Interprofessional Care, 19, 8-20. doi: 10.1080/13561820500081604

Darlow, B., Brown, M., Gallagher, P., Gray, L., McKinlay, E., Purdie, G., . . Pullon, S. (2018). Longitudinal impact of interprofessional education on attitudes, skills and career trajectories: A protocol for a quasiexperimental study in New Zealand. BMJ Open, 8(1). doi:10.1136/bmjopen-2017-018510

Dow, A. W., DiazGranados, D., Mazmanian, P. E., \& Retchin, S. M. (2014). An exploratory study of an assessment tool derived from the competencies of the interprofessional education collaborative. Journal of Interprofessional Care, 28(4), 299-304. doi:10.3109/13561820.2014.891573

Fox, L., Onders, R., Hermansen-Kobulnicky, C. J., Nguyen, T., Myran, L., Linn, B., \& Hornecker, J. (2018). Teaching interprofessional teamwork skills to health professional students: A scoping review. Journal of Interprofessional Care, 32(2), 127-135. doi:10.1080/13561820.2017.1399868

Greenwood, E., \& Bales, R. F. (1950). Interaction process analysis: A method for the study of small groups. American Sociological Review, 15(5). doi:10.2307/2086941

Interprofessional Education Collaborative (2016). Core Competencies for Interprofessional Collaborative Practice: Report of an Expert Panel. Washington, DC. Retrieved from: https://ipecollaborative.org/uploads/IPEC-Core-Competencies.pdf

Johnson, K. F., \& Freeman, K. L. (2014). Integrating interprofessional education and collaboration competencies (IPEC) into mental health counselor education. Journal of Mental Health Counseling. 36(4) 328-344 
Jones, A., \& Jones, D. (2011). Improving teamwork, trust and safety: An ethnographic study of an interprofessional initiative. Journal of Interprofessional Care, 25, 175-181. doi: $10.3109 / 13561820.2010 .520248$

Kenaszchuk, C., Reeves, S., Nicholas, D., \& Zwarenstein, M. (2010). Validity and reliability of a multiple-group measurement scale for interprofessional collaboration. BMC Health Services Research, 10(1). doi:10.1186/1472-6963-10-83

Lawlis, T. R., Anson, J., \& Greenfield, D. (2014). Barriers and enablers that influence sustainable interprofessional education: a literature review. Journal of Interprofessional Care. 28(4), 305-310. DOI: 10.3109/13561820.2014.895977

Luecht, R. M., Madsen, M. K., Taugher, M. P., \& Petterson, B. J. (1990). Assessing professional perceptions: Design and validation of an interdisciplinary education perception scale. Journal of Allied Health, 19(2), 181-191.

McDonald, M. B., Bally, J. M., Ferguson, L. M., Lee Murray, B, FowlerKerry, S. E., \& Anunson, J. M. S., (2009). Knowledge of the professional role of others: A key interprofessional competency. Nurse Education in Practice, 10, 238-242. doi:10.1016/j.nepr.2009.11.012

Norris, J., Carpenter, J. G., Eaton, J., Guo, J., Lassche, M., Pett, M. A., \& Blumenthal, D. K. (2015). The development and validation of the interprofessional attitudes scale: Assessing the interprofessional attitudes of students in the health profession. Academic Medicine. 90, 1394- 1400. DOI: 10.1097IAMCM.0000000000000764

Pechak, C., Summers, C., Schoen, B., Padilla, M., Lara P., Velasco, J., \& Capshaw, S. (2018). Development and preliminary assessment of interprofessional education focused on vulnerable populations. Journal of Allied Health, 47(3), e77-e83.

Pechak, C., Summers, C., \& Velasco, J. (2018). Improved knowledge following an interprofessional interpreter-use training. Journal of Allied Health, 47(3), 159-166.

Reeves, S. \& Barr, H. (2016). Twelve steps to evaluating interprofessional education. Journal of Taibah University Medical Sciences, 11(6), 601-605.

Reeves, S., Perrier, L., Goldman, J., Freeth, D., \& Zwarenstein, M. (2013). Interprofessional education: Effects on professional practice and healthcare outcomes (update). Cochrane Database of Systematic Reviews, 3, CD002213. doi:10.1002/14651858.CD002213.pub3

Reeves, S., Tassone, M., Parker, K., Wagner, S. J., Simmons, B. (2012). Interprofessional education: An overview of key developments in the past three decades. IOS Press. 41, 233-245. 
Reeves, S., Zwarenstein, M., Goldman, J., Barr, H., Freeth, D., Hammick, M., \& Koppel, I. (2009). Interprofessional education: Effects on professional practice and health care outcomes (Review). The Cochrane Library. 4, 1-22.

Sargeant, J., Loney, E., \& Murphy, G. (2008). Effective Interprofessional Teams: “Contact Is Not Enough" to Build a Team. Journal of Continuing Education in the Health Professions, 28, 228-234. doi: 10.1002/chp

Suter, E., Arndt, J., Arthur, N., Parboosingh, J., Taylor, E., \& Deutschlander, S. (2009). Role understanding and effective communication as core competencies for collaborative practice. Journal of Interprofessional Care, 23, 41-51. doi: 10.1080/13561820802338579

Vincent, C. (2015). Patient safety (2nd ed.). Oxford, UK: Wiley-Blackwell.

World Health Organization. (2010). Framework for action on interprofessional education \& collaborative practice. Retrieved from: http://www.who.int/hrh/resources/framework_action/en 


\section{Appendix}

Appendix A. Interprofessional Attitudes Scale (IPAS)

\section{Teamwork, Roles, and Responsibilities}

1.1. Shared learning before graduation will help me become a better team worker.

1.2. Shared learning will help me think positively about other professionals.

1.3. Learning with other students will help me become a more effective member of a health care team.

1.4. Shared learning with other health sciences students will increase my ability to understand clinical problems.

1.5. Patients would ultimately benefit if health sciences students worked together to solve patient problems.

1.6. Shared learning with other health sciences students will help me communicate better with patients and other professionals.

1.7. I would welcome the opportunity to work on small-group projects with other health sciences students.

1.8. It is not necessary for health sciences students to learn together.

1.9. Shared learning will help me understand my own limitations.

\section{Patient-Centeredness}

2.1. Establishing trust with my patients is important to me.

2.2. It is important for me to communicate compassion to my patients.

2.3. Thinking about the patient as a person is important in getting treatment right.

2.4. In my profession, one needs skills in interacting and co-operating with patients.

2.5. It is important for me to understand the patient's side of the problem.

\section{Interprofessional Biases}

3.1. Health professionals/students from other disciplines have prejudices or make assumptions about me because of the discipline I am studying.

3.2. I have prejudices or make assumptions about health professionals/students from other disciplines.

3.3. Prejudices and assumptions about health professionals from other disciplines get in the way of delivery of health care.

\section{Diversity \& Ethics}

It is important for health professionals to:

4.1. Respect the unique cultures, values, roles/responsibilities, and expertise of other health professions.

4.2. Understand what it takes to effectively communicate across cultures.

4.3. Respect the dignity and privacy of patients while maintaining confidentiality in the delivery of team-based care.

4.4. Provide excellent treatment to patients regardless of their background (e.g. race, ethnicity, gender, sexual orientation, religion, class, national origin, immigration status, or ability). 


\section{Community-Centeredness}

It is important for health professionals to:

5.1. Work with public health administrators and policy makers to improve delivery of health care.

5.2. Work on projects to promote community and public health.

5.3. Work with legislators to develop laws, regulations, and policies that improve health care.

5.4. Work with non-clinicians to deliver more effective health care.

5.5. Focus on populations and communities, in addition to individual patients, to deliver effective health care.

5.6. Be advocates for the health of patients and communities. 


\section{Vita}

Francesca Julia Hernandez was born and raised in El Paso, Texas. In 2017, Francesca was awarded a full-ride scholarship from the Terry Foundation to complete her undergraduate education at the University of Texas at El Paso (UTEP). She graduated Summa Cum Laude with her Bachelor of Science in Rehabilitation Sciences with a concentration in Speech-Language Pathology in 2019. Francesca is currently pursuing her Master of Science in Speech-Language Pathology with a Concussion Management Certificate at UTEP with an anticipated graduation date of May 2021.

Francesca worked as a graduate research assistant under the mentorship of Dr. Patricia Lara and Dr. Connie Summers. Her research focused on the effects of interprofessional education (IPE) experiences for students from rehabilitation sciences graduate programs. Francesca has presented her research at the UTEP Graduate Student Research Expo.

Contact Information: francescah99@gmail.com This thesis was typed by Francesca Julia Hernandez. 